\title{
Valvular aortic stenosis causing angiodysplasia and acquired von Willebrand's disease: Heyde's syndrome
}

\author{
Aaysha Kapila, ${ }^{1}$ Lovely Chhabra, ${ }^{2}$ Atul Khanna ${ }^{3}$
}

${ }^{1}$ ETSU, Johnson City, Tennessee, USA

${ }^{2}$ Department of Cardiology, Hartford Hospital, University of Connecticut School of Medicine, Hartford, CT, USA ${ }^{3}$ Department of

Gastroenterology, ETSU,

Johnson City, Tennessee, USA

\section{Correspondence to}

Dr Lovely Chhabra,

lovids@hotmail.com

Accepted 27 February 2014

\section{DESCRIPTION}

A 70-year-old man with a medical history of hypertension, coronary artery disease and aortic stenosis (AS) was admitted with symptoms of worsening chest pain and exertional dyspnoea. He also reported melanotic stools and was found to be profoundly anaemic with a haematocrit value of $25 \%$. His last hematocrit a month prior was $36 \%$. Laboratory data revealed normal vitamin $\mathrm{B}_{12}$ and folate levels, but iron levels were consistent with mild iron deficiency anaemia (serum iron $45 \mu \mathrm{g} / \mathrm{dL}$, transferrin saturation $20 \%$ and serum ferritin $68 \mathrm{ng} / \mathrm{mL}$ ). Stool guaiac test was positive. He underwent an oesophagogastroduodenoscopy, which showed stomach wall coated with old blood with no active bleeding lesions (figure 1A), 10-12 petechial submucosal haemorrhages in the jejunum and active bleeding in the second part of the duodenum (D2; figure $1 \mathrm{~B}) . \mathrm{He}$ underwent clipping at the bleeding site (figure 1C). Mesenteric angiogram showed hypervascularity and extravasation seen in the second part of the duodenum supplied by the superior mesenteric and gastroduodenal artery (figure 2A,B). Transthoracic echocardiogram revealed severe valvular AS with aortic valve area of $0.7 \mathrm{~cm}^{2}$, and mean transvalvular gradient of $40 \mathrm{~mm} \mathrm{Hg}$. He received 6 units of packed red blood cells. Octreotide infusion was administered followed by clipping of the gastroduodenal artery, which resulted in stabilisation of his haematocrit. He was subsequently referred for an aortic valve replacement and was discharged in a clinically stable condition. von Willebrand factor (vWF) levels returned within normal limits. An outpatient follow-up after 2 months confirmed clinical stability. His haemogram remained stable without requiring any further blood transfusions.

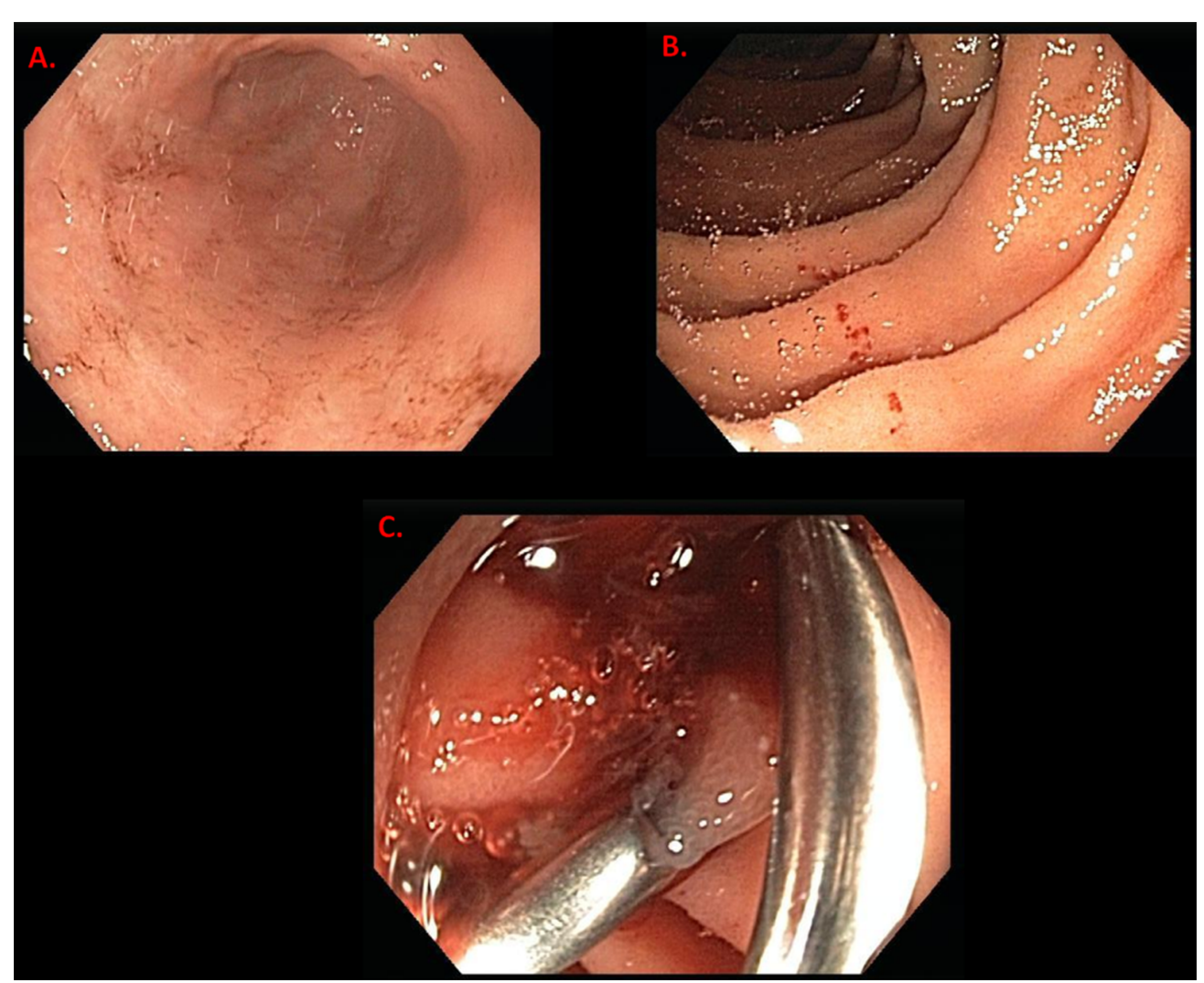

Figure 1 (A) Endoscopic image showing stomach wall coated with old blood, with no active bleeding lesions. (B) Endoscopic image of proximal jejunum revealing 10-12 petechial haemorrhages, showing oozing of blood which continued despite irrigation and suctioning. No mucosal lesions identifiable. (C) Distal second part of the duodenum, D2, revealing moderate amount of fresh blood. No ulcer or aberrant blood vessel seen on endoscopy. Two haemostatic clips applied to localised area with slowing of bleeding. 


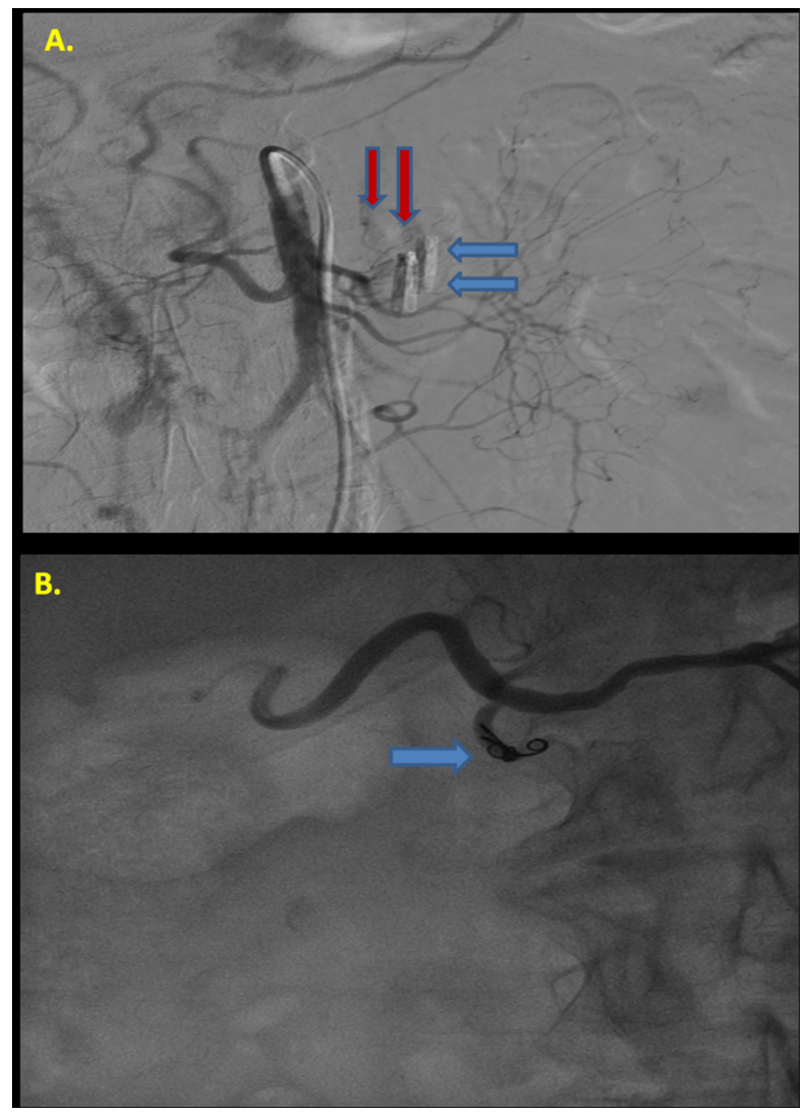

Figure 2 (A) Mesenteric angiogram showing hypervascularity and extravasation seen in the second part of the duodenum supplied by the superior mesenteric and gastroduodenal artery. Red arrows indicate bleeding at the site of the superior mesenteric artery. Black arrows showing clips placed in the second part of the duodenum.

(B) Successful haemostasis achieved in the gastroduodenal artery, as indicated by the blue arrow.

The patient was diagnosed with Heyde's syndrome given his severe AS, submucosal haemorrhages (angiodysplasia) and active bleeding in the small bowel. Other diagnoses were excluded by negative endoscopic and colonoscopic findings for any underlying gastrointestinal (GI) malignancy or other structural diseases such as diverticulosis. Bleeding from angiodysplasia in patients with AS has been named Heyde's syndrome, as it was first described in 1958 by Dr Edward C Heyde. ${ }^{1}$ The likely mechanism for the GI bleeding in these patients is a decreased GI perfusion secondary to severe AS, which leads to hypoxia-induced dilation of the blood vessels, thus hastening up the development of fixed vasodilation and genesis of angiodysplasia. ${ }^{2}$ Second, vWF multimers, which mediate platelet adhesion for haemostasis, undergo degeneration by high shear stress across the stenotic aortic valve, leading to coagulation abnormalities, which is a state of acquired von Willebrand's disease (Type 2AvWF disease). ${ }^{3}$ Despite the fact that this is a well-described entity in the literature, the association between AS and intestinal angiodysplasia has remained controversial among the experts, as retrospective studies and cohort studies have yielded different conclusions. ${ }^{4}$ Nevertheless, the evidence that AS is the primary cause of the coagulopathy is much stronger than the evidence for a casual association with angiodysplasia.

Angiodysplasia is the most common vascular abnormality of the GI tract and is the second most common cause of lower GI bleeding in elderly patients after diverticulosis. In $40-60 \%$ of patients with gastric and duodenal angiodysplasia, multiple lesions are observed at endoscopy. Colonic lesions are associated in $15-20 \%$ of these patients and are often multiple than single. To diagnose and treat patients with suspected angiodysplasia, the diffuse location of lesions and the propensity for multiplicity must be considered. The lesions of Heyde's syndrome are often multiple, and may frequently involve ascending colon or the caecum. Whenever feasible, colonoscopy and gastroduodenoscopy are the initial diagnostic modalities of choice. Selective mesenteric angiography may serve as a useful diagnostic technique for angiodysplasias, especially in patients with massive bleeding where a colonoscopic diagnosis is often difficult. Small bowel capsule endoscopy is an advanced diagnostic technique, and is often very helpful in diagnosing small bowel angiodysplasia which accounts for about $30-40 \%$ of the cases of obscure GI bleeding. To make the diagnosis of Heyde's syndrome in an elderly patient with unexplained anaemia or occult bleeding, other diagnostic possibilities must be excluded. Thus, exclusion criteria for the diagnosis of Heyde's syndrome include ruling out other possibilities such as an underlying GI malignancy, coeliac disease and/or nutritional deficiency (such as vitamin $\mathrm{B}_{12}$ or folate deficiency). The presence of angiodysplasia on sigmoidoscopy or colonoscopy, or a failure of the investigations to find any clear site of GI bleeding, should raise the possibility of Heyde's syndrome, especially in patients with known AS. ${ }^{6}$

Valve replacement surgery alone can result in cure of Heyde's syndrome. Reversal of symptoms can occur in cases of either restenosis of the aortic valve or mismatch of prosthesis.

\section{Learning points}

- Bleeding from angiodysplasia in patients with aortic stenosis has been called Heyde's syndrome.

- To make the diagnosis of Heyde's syndrome, presence of other diagnostic possibilities such as an underlying gastrointestinal malignancy, coeliac disease and/or nutritional deficiency (such as vitamin $B_{12}$ or folate deficiency) must be excluded.

- Plausible explanations for the association between aortic valve stenosis and gastrointestinal bleeding include decreased gastrointestinal perfusion causing hypoxia-induced dilation of the blood vessels and induction of type 2A von Willebrand's disease.

Competing interests None.

Patient consent Obtained.

Provenance and peer review Not commissioned; externally peer reviewed.

\section{REFERENCES}

1 Heyde EC. Gastrointestinal bleeding in aortic stenosis. N Engl J Med 1958;259:196

2 Saad RA, Lwaleed BA, Kazmi RS. Gastrointestinal bleeding and aortic stenosis (Heyde syndrome): the role of aortic valve replacement. J Card Surg 2013;28:414-16.

3 Vincentelli A, Susen S, Le Tourneau T, et al. Acquired von Willebrand syndrome in aortic stenosis. N Engl J Med 2003;349:343-9.

4 Bhutani MS, Gupta SC, Markert RJ, et al. A prospective controlled evaluation of endoscopic detection of angiodysplasia and its association with aortic valve disease. Gastrointest Endosc 1995:42:398-402.

5 Greenstein RJ, McElhinney AJ, Reuben D, et al. Colonic vascular ectasias and aortic stenosis: coincidence or causal relationship? Am J Surg 1986;151:347-51.

6 Massyn MW, Khan SA. Heyde syndrome: a common diagnosis in older patients with severe aortic stenosis. Age Ageing 2009:38:267-70. 
Copyright 2014 BMJ Publishing Group. All rights reserved. For permission to reuse any of this content visit http://group.bmj.com/group/rights-licensing/permissions.

BMJ Case Report Fellows may re-use this article for personal use and teaching without any further permission.

Become a Fellow of BMJ Case Reports today and you can:

- Submit as many cases as you like

- Enjoy fast sympathetic peer review and rapid publication of accepted articles

- Access all the published articles

- Re-use any of the published material for personal use and teaching without further permission

For information on Institutional Fellowships contact consortiasales@bmjgroup.com

Visit casereports.bmj.com for more articles like this and to become a Fellow 